Research Article

\title{
The PIN1 family gene PVPIN1 is involved in auxin-dependent root emergence and tillering in switchgrass
}

\author{
Kaijie $\mathrm{Xu}^{1,2}$, Fengli Sun ${ }^{1}$, Yongfeng Wang ${ }^{1}$, Lili Shi ${ }^{3}$, Shudong Liu ${ }^{1}$ and Yajun $\mathrm{Xi}^{1}$ \\ ${ }^{1}$ State Key Laboratory of Crop Stress Biology for Arid Areas, Northwest A\&F University, Yangling, Shaanxi, \\ China. \\ ${ }^{2}$ Institute of Cotton Research, Chinese Academy of Agricultural Sciences, Anyang, Henan, China. \\ ${ }^{3}$ Handan Academy of Agricultural Sciences, Handan, Hebei, China
}

\begin{abstract}
Switchgrass (Panicum virgatum L.; family Poaceae) is a warm-season C4 perennial grass. Tillering plays an important role in determining the morphology of aboveground parts and the final biomass yield of switchgrass. Auxin distribution in plants can affect a variety of important growth and developmental processes, including the regulation of shoot and root branching, plant resistance and biological yield. Auxin transport and gradients in plants are mediated by influx and efflux carriers. PVPIN1, a switchgrass PIN1-like gene that is involved in regulating polar transport, is a putative auxin efflux carrier. Neighbor-joining analysis using sequences deposited in NCBI databases showed that the PVPIN1 gene belongs to the PIN1 family and is evolutionarily closer to the Oryza sativa japonica group. Tiller emergence and development was significantly promoted in plants subjected to PVPIN1 RNA interference (RNAi), which yielded a phenotype similar to that of wild-type plants treated with the auxin transport inhibitor TIBA (2,3,5-triiodobenzoic acid). A transgenic approach that induced PVPIN1 gene overexpression or suppression altered tiller number and the shoot/root ratio. These data suggest that PVPIN1 plays an important role in auxin-dependent adventitious root emergence and tillering.
\end{abstract}

Keywords: Auxin transporter, PvPIN1 gene, TIBA treatment, tillering, switchgrass.

Received: October 10, 2014; Accepted: May 28, 2015.

\section{Introduction}

Switchgrass (Panicum virgatum L.; family Poaceae) is a perennial warm-season $\mathrm{C} 4$ grass. In recent years, switchgrass has received increasing attention as a highly versatile feedstock used for soil and water conservation, livestock feeding and bioethanol production (Casler, 2012; Parrish et al., 2012). However, the competition between switchgrass and crops for water and arable lands may exacerbate current food security challenges (Varvel et al., 2008). Therefore, maximizing the use of various nonirrigated marginal croplands and improving the resistance of switchgrass may be plausible approaches to address the above concern.

One of the practical strategies to enhance plant production and anti-stress abilities is to use molecules involved in various stages of plant growth. The plant phytohormone auxin regulates numerous developmental processes during plant growth, including growth direction, shoot and root branching, and differentiation of vascular tissue (Xu et al., 2005). Auxin also plays an important role

Send correspondence to Yajun Xi. Northwest A\&F University, Yangling, Shaanxi, 712100, China. E-mail: xiyajun11@126.com in plant resistance and biological yield (Wang et al., 2007; Seo et al., 2009). Auxin is generally thought to be synthesized in young apical tissues and then transported down to the maturing stem and root via a polar transport system (Crozier et al., 2000). The cell-to-cell polar transport of auxin requires influx and efflux carrier proteins (Muday and DeLong, 2001) and is important for controlling critical developmental processes by reorienting appropriate growth in response to various environmental stimuli. For these reasons, there is considerable research into auxin transport.

The PIN family of genes is involved in regulating polar transport, and many effects of auxin can be blocked by inhibitors or mutations that prevent the polar transport of auxin (Rosen et al., 1999). The PIN family in Arabidopsis has eight members (AtPIN1 to AtPIN8) (Chen et al., 2012). Each member exhibits a unique tissue-specific expression pattern and subcellular localization (Paponov et al., 2005). PIN1 is an efflux-facilitating family member (Friml et al., 2003; Blilou et al., 2005) that encodes a putative auxin efflux carrier protein. PIN1-type proteins determine the direction of cell-to-cell auxin transport through their asymmetric subcellular localizations in the plasma membrane (Winiewska et al., 2006; Huang et al., 2010). 
In Arabidopsis, a mutation in the PIN1 gene (Okada et al., 1991) results in failure to establish endogenous auxin gradients, leading to the abnormal formation and development of shoots, roots, embryos and inflorescence (Vernoux et al., 2000; Benková et al., 2003; Reinhardt et al., 2003; Weijers and J1rgens, 2005). Homologs of the PIN1 gene have also been identified in other plant species, including Setaria italia (GenBank: XM_004953823.1), Zea (Forestan and Varotto, 2010), Oryza sativa (Xu et al., 2005) and Sorghum bicolor (Paterson et al., 2005). In particular, overexpression of the rice OSPINI gene (previously known as $R E H 1)$ significantly increases the primary root length and lateral root number (Luschnig et al., 1998). The OsPIN1 protein is very important for determining tiller angle and number (Xu et al., 2005).

Like rice, switchgrass produces numerous adventitious roots that are essential for plant development, particularly for stress resistance. Use of the polar auxin transport inhibitor $N$-1-naphthylphthalamic acid (NPA) or 2,3,5-triiodobenzoic acid (TIBA) may block the development of rice root collars (the junction between the root and stem) but promote the initiation and growth of adventitious and lateral roots (Zhou et al., 2003). Auxin inhibits shoot branching (Chatfield et al., 2000) and the ectopic distribution of auxin could influence flower bud development at various stages. Auxin signaling may also play a key role in axillary bud development (Leyser, 2003).

Even though roles for PINI in the formation and development of adventitious roots and tillers have been identified in many plant species, the function of PIN1 in switchgrass has not been investigated. In this report, we examined the characteristics of the PIN1 gene in switchgrass and its effects on the development of adventitious roots and tillers. The findings described here enhance our understanding of PIN1 gene functions and may also stimulate basic genetic research into switchgrass.

\section{Materials and Methods}

\section{Plant materials, explant sterilization and callus induction}

A switchgrass cultivar 'Xiji 2' bred from the American 'Alamo' cultivar was used as the transgenic acceptor to induce callus formation. Mature caryopses were picked from a single plant and then surface-sterilized for callus induction. The resulting caryopses were further processed on two consecutive days (Xi et al., 2009). Initially, they were surface-sterilized with $70 \%$ ethanol for $1 \mathrm{~min}$ and $15 \%$ sodium hypochlorite for $75 \mathrm{~min}$, rinsed 3-4 times with sterile water and left overnight at $4{ }^{\circ} \mathrm{C}$. On the following day, they were sterilized with $15 \%$ sodium hypochlorite for $30 \mathrm{~min}$ and rinsed 3-4 times with sterile water. Next, sterilized caryopses were placed on induction medium (M5) composed of Murashige and Skoog (MS) basal medium supplemented with $22.6 \mu \mathrm{M}$ 2,4-D (2,4-Dichlorophenoxy), 0.2 $\mathrm{mg} / \mathrm{L}$ 6-BA (6-Benzylaminopurine), $1 \mathrm{mg} / \mathrm{L}$ picloram, and $1.5 \%$ sucrose and $1.5 \%$ mannitol $(\mathrm{w} / \mathrm{v})$ as the carbon sources; this medium was subsequently solidified with $0.7 \%$ agarose $(\mathrm{w} / \mathrm{v})$. The cultures were incubated in the dark at $25^{\circ} \mathrm{C}$ for 4-6 weeks, after which calli were obtained and embryogenic calli were selected for transgenesis.

\section{Switchgrass PVPIN1 gene cloning}

Total RNA extraction (Invitrogen, Carlsbad, CA) from switchgrass shoots at the V3 stage (Moore et al., 1991) and cDNA synthesis (Takara, Shiga, Japan) were done as described in the manufacturers' protocols. Based on the transcriptomes of different tiller mutants, sequences similar to the PIN1 gene were selected as differentially expressed genes and primers were designed for PIN1 gene cloning. The open reading frame (ORF) of the PIN1 gene was cloned from switchgrass. Polymerase chain reaction (PCR) amplification products were analyzed electrophoretically in $1 \%$ agarose/ethidium bromide gels. The fragments were subsequently cloned and inserted into T-easy vectors (Promega, Madison, WI), transformed in Escherichia coli DH5 $\alpha$ and sent to Life Technologies (Carlsbad, CA) for sequencing.

\section{Construction of RNAi and expression vectors for PVPIN1}

An RNA interference (RNAi) construct was generated to investigate the effects of loss of PvPIN1 function. The pTCK303 vector (Wang et al., 2004) contains a chimeric hygromycin phosphotransferase (HPT) gene and a $\beta$-glucuronidase (GUSa) gene, both under control of the CaMV35S promoter. According to the pTCK303 vector structure, a 491-bp fragment from the ORF of PvPIN1 was amplified using two sets of primers ( $\mathrm{dF} 1$ and $\mathrm{dR} 1)$; another fragment was similarly amplified using primers $\mathrm{dF} 2$ and dR2 (Table 1). The resulting DNA fragments were first cloned into T-easy vectors (Promega) for sequence verification by Life Technologies. After confirmation, the two vectors and the pTCK 303 vector were digested using double digestion and recycled using a gel extraction kit (Tiangen Biotech, Beijing, China). The fragments were subsequently inserted separately into the pTCK 303 vector using T4 ligase. The chimeric RNAi vector was transformed into $\mathrm{DH} 5 \alpha$ for transgenesis.

To study PvPIN1 gain of function, the full-length coding region of the $P v P I N 1$ gene was amplified using the F1/R1 primer pairs with $B a m \mathrm{HI}$ and SpeI restriction sites, respectively. The resulting PCR product was cloned in the T-easy vector (Promega) and then inserted into the pTCK303 vector. Plasmid DNAs were extracted according to the manufacturer's protocol (Plasmid DNA extract kit, Tiangen Biotech). 
Table 1 - Sequences of the primers used in this work.

\begin{tabular}{|c|c|c|}
\hline Primer name & Sequences $\left(5^{\prime}-3^{\prime}\right)$ & Enzyme sites \\
\hline $\mathrm{F}$ & ATGATTACGGGGGCGGACTT & \\
\hline $\mathrm{R}$ & TCACAACCCGAGCAGGATGT & \\
\hline F1 & CGGGATCCCGATGATTACGGGGGCGGACTT & Bam HI \\
\hline R1 & GACTAGTCTCACAACCCGAGCAGGATGT & SpeI \\
\hline $\mathrm{dF} 1$ & GACTAGTCGGCATCAACCGCTTCGTCGC & SpeI \\
\hline $\mathrm{dR} 1$ & CGAGCTCGTGTATCTTGCCGTCCTCCTT & SacI \\
\hline $\mathrm{dF} 2$ & GGGGTACCCCGGCATCAACCGCTTCGTCGC & KpnI \\
\hline $\mathrm{dR} 2$ & CGGGATCCCGTGTATCTTGCCGTCCTCCTT & BamHI \\
\hline $\mathrm{HphF}$ & GGAGCATATACGCCCGGAGT & \\
\hline HphR & GTTTATCGGCACTTTGCATCG & \\
\hline HphF1 & TTCTACACAGCCATCGGTCCA & \\
\hline HphR1 & TTAGCCAGACGAGCGGGTTC & \\
\hline $\mathrm{qF}$ & GAGTTCAGCTTCGGGAACAG & \\
\hline $\mathrm{qR}$ & CTCGAAGTTCCACCTGAAGC & \\
\hline
\end{tabular}

\section{Particle bombardment and genetic transformation}

A plasmid containing RNAi and PvPIN1 gene expression vectors was extracted according to the manufacturer's protocol (Plasmid DNA extraction kit, Tiangen Biotech). Before particle bombardment, the embryogenic calli were placed in a $4-\mathrm{cm}^{2}$ circle monolayer on $\mathrm{MSH}$ (Hypertonic MS) medium in a 9-cm dish containing MS medium basal medium with $22.6 \mu \mathrm{M}$ 2,4-D and $0.4 \mathrm{M}$ mannitol (Sigma, St. Louis, MO) followed by a 4-6 h osmotic treatment in the dark at $25^{\circ} \mathrm{C}$. Gold particles $(1 \mu \mathrm{m}$, Bio-Rad, Hercules, CA) were soaked with the abovementioned plasmid DNA (Vain et al,. 1993). For each bombardment shot, $1 \mu \mathrm{g}$ of plasmid DNA and $250 \mu \mathrm{g}$ of gold particles were used. The bombardment was done using a $1100 \mathrm{psi}$ He inflow with a target distance of $9 \mathrm{~cm}$. Thereafter, the bombarded calli were incubated on MSH medium overnight.

\section{Transgenic plant selection and regeneration}

PvPIN1 gene function was verified by selecting embryogenic calli and bombarding them with microprojectiles carrying pTCK303 vectors (containing the RNAi and overexpression vectors) with a gene gun (Bio-Rad). Initially, the bombarded calli were transferred to the recovery medium and $22.6 \mu \mathrm{M} 2,4-\mathrm{D}$ was added to the MS basal medium one week later. The recovered calli were selected on selection medium that contained hygromycin B $(50 \mathrm{mg} / \mathrm{L})$ at $25^{\circ} \mathrm{C}$ in the dark for $4-5$ weeks. The calli were cultured at $25{ }^{\circ} \mathrm{C}$ on regeneration medium containing kinetin (KT, 2 $\mathrm{mg} / \mathrm{L}$ ) to induce cell division and callus differentiation and development. An illumination intensity of 12,000 $\mu \mathrm{mol} /\left(\mathrm{m}^{2} . \mathrm{s}\right)$ and a $16 / 8 \mathrm{~h}$ (light/dark) photoperiod was used until the calli reached bud differentiation. The seedlings were then transplanted into soil in containers for further root development on a $12 \mathrm{~h}$ photoperiod at $28 / 25^{\circ} \mathrm{C}$ and $60 \%$ humidity in a phytotron.

\section{Molecular analyses of transgenic plants}

The PvPIN1 gene sequences were inserted between the two reporter genes and controlled by a UBi-1 promoter. The GUS reporter gene contains a catalase intron within the coding sequence to ensure eukaryote-specific expression. The seedlings were allowed to grow to the V3 stage and DNA samples from each plant were extracted using the $2 \mathrm{x}$ CTAB method. These DNA samples were screened using PCR with the Hyg and GUSa primers (Table 1) and Taq DNA polymerase (Fermentas, Burlington, ON, Canada). The expected product sizes were 612 bp for Hyg and $1,081 \mathrm{bp}$ for GUSa. The components and conditions of the PCR were similar to those used for PvPIN1 gene cloning, except that the templates used were the genomic DNA of regenerated seedlings and the extension time was $90 \mathrm{~s}$. The resulting PCR products were analyzed by electrophoresis in $1 \%$ agarose/ethidium bromide gels (Xi et al., 2009).

For Southern blot hybridization analysis, genomic DNA was extracted from $250 \mathrm{mg}$ of fresh young leaves of transgenic seedlings using a Plant Genomic DNA kit (Tiangen Biotech). The DNA content of the samples was quantified prior to digestion with the restriction enzyme EcoRI (Takara), which only digests the T-DNA region, and each sample was then hybridized with the hygromycin probe. Briefly, $12 \mu \mathrm{g}$ of DNA from each sample was digested overnight and loaded onto each lane. The hybridization probe (hph) was labeled with digoxigenin (DIG, Roche, Basel, Switzerland) by PCR. The primers for the hybridization probe were HphF1 and HphR1, and the expected product size was $590 \mathrm{bp}$. Gel electrophoresis, DNA blotting and hybridization were done according to the manufacturer's 
instructions. The hybridization signals were detected using the chemiluminescent substrate CSPDStar (Roche).

Southern blotting was used to examine the insertional copy numbers of individual transgenic plants. To eliminate differences in the genetic background of the plants, ten separate transgenic lines were selected from each group (PvPIN1-Ri, CK (wild-type) and PvPIN1-OE) that had strong PCR bands and Southern blot results for phenotypic analysis. The old and young tillers and roots of these plants were dissected and genomic DNA was extracted. RNA quality and quantity were analyzed using an Agilent 2100 Bioanalyzer (Agilent Technologies, Santa Clara, CA) and gel electrophoresis. Meanwhile, the apical and basal shoots and roots of selected transgenic plants were dissected and processed for enzyme-linked immunosorbent assays (ELISAs) for endogenous auxin; the assays were done at the China Agricultural University (Yang et al., 2001). Phenotypic data for the three groups were collected and analyzed using Excel 2007 (Microsoft, Redmond, WA) and the figures were drawn with Origin 7.5 (Origin Lab, Northampton, MA).

\section{qRT-PCR Analysis}

Quantitative reverse transcriptase (qRT)-PCR (Takara) was used to quantify PvPIN1 expression in transgenic (containing RNAi and overexpressing $P v P I N 1$ ) and wild-type plants. Total RNA was extracted from the young tillers of wild-type and transgenic switchgrasses with TriReagent (Invitrogen) and reverse transcribed for cDNA according to the manufacturer's protocols (Takara). SYBR Green (Takara) was used as the reporter dye. The qRT-PCR primers are listed in Table 1. The cycle thresholds were determined using a Bio-Rad CFX96 sequence detection system with a volume of $25 \mu \mathrm{L}$ containing $12.5 \mu \mathrm{L}$ of TaqMan Master Mix SYBR Premix ExTaq (Takara). The cycling conditions were as follows: $95^{\circ} \mathrm{C}$ for $10 \mathrm{~min}$, followed by 40 cycles of $95^{\circ} \mathrm{C}$ for $15 \mathrm{~s}$ and $60{ }^{\circ} \mathrm{C}$ for $1 \mathrm{~min}$. Two microliters of cDNA ( $80 \mathrm{ng}$ ) per sample was used for PCR amplification. The data were normalized using the level of switchgrass $\beta$-actin transcripts. The primers were 5'-CACTGGAATGGTCAAGGCTG-3' (forward primer) and 5'-CTCCATGTCATCCCAGTTG-3' (reverse primer) (Song et al., 2012).

\section{TIBA treatment}

To determine the role of PvPIN1 in auxin transport, TIBA was used to disrupt the polar transport of this hormone in the lateral buds and stem nodes. The top nodes at the E4 stage represent lateral bud formation and the stem nodes with lateral shoots were collected and cut into $3-\mathrm{cm}$ pieces with the node in the middle. The nodal segments were surface sterilized with $70 \%$ ethanol for $1 \mathrm{~min}$, followed by $15 \% \mathrm{NaClO}$ ( $9 \%$ effective chlorinity) for $15 \mathrm{~min}$, and then rinsed three times with sterile water. The resulting materials were then inoculated on MSB medium (MS me- dium supplemented with $3 \mathrm{mg} / \mathrm{L}$ 6-BA, $3 \%$ sucrose and solidified with $0.7 \%$ agar). The buds grew to $3-5 \mathrm{~cm}$ in length after exposure to light at $25^{\circ} \mathrm{C}$ for 2-3 weeks. After bud removal, the nodes were further subcultured on MSB medium supplemented with $10 \mu \mathrm{M}$ TIBA for two weeks (the TIBA solution was sterilized by filtration and added to the sterilized MSB medium).

\section{Results}

\section{PvPIN1 gene cloning and sequence analysis}

Analysis of the transcriptome results for switchgrass tillering mutants indicated that the PIN1 gene was differentially expressed. Based on the sequence in the transcriptome database, the PvPIN1 gene was amplified from the cDNA of switchgrass young tillers with the primer pairs F and R (Table 1). The ORF of the PvPIN1 gene contained 1,788 nucleotides that encoded a protein with 596 amino acid residues and had a calculated molecular mass of 64.7 $\mathrm{kDa}$. Based on the hydropathy and transmembrane motif analyses, the deduced amino acid sequence of PvPIN1 was similar to that of the OsPIN1 protein, which contains three significant motifs: a putative hydrophilic core and two putative transmembrane domains on either side (Figure 1) (Luschnig et al., 1998; Xu et al., 2005). The PvPIN1 protein showed $94 \%$ sequence homology with OsPIN1 (sequence information collected from the NCBI database) and neighbor-joining phylogeny showed that PvPIN1 was grouped with the Oryza sativa japonica clade (Figure 2). Based on the foregoing analyses, this homologous switchgrass gene was provisionally named the PvPIN1 gene.

\section{Regeneration of transgenic switchgrass}

After selection on hygromycin and regeneration of transgenic calli, the transgenic seedlings (Figure 3) were obtained and planted in a greenhouse. When the seedlings reached the V3 stage, DNA from individual plants was extracted using the cetyltrimethylammonium bromide (CTAB) method and the DNA samples were screened by PCR using the Hph (621 bp) and GUSa primers (1081 bp). The results showed that $61.9 \%$ of the $\mathrm{T}_{1}$ plants were positive for Hph and GUSa gene insertions (Figure 4A). Fortyfive seedlings contained the overexpressed vector and 39 seedlings contained the RNAi vector. To exclude false positives produced during PCR amplification, true transgenics were identified based on clear, strong PCR bands (Xi et al., 2009).

To further eliminate false positives, Southern blot hybridization analysis was used to screen the putatively positive transgenic plants. The restriction enzyme EcoRI, which only digests once in the T-DNA region, was used to digest the genomic samples that were then hybridized with the hygromycin probe. Hybridization signals corresponding to the high-molecular weight bands and fragments of 
TMpred output for unknown

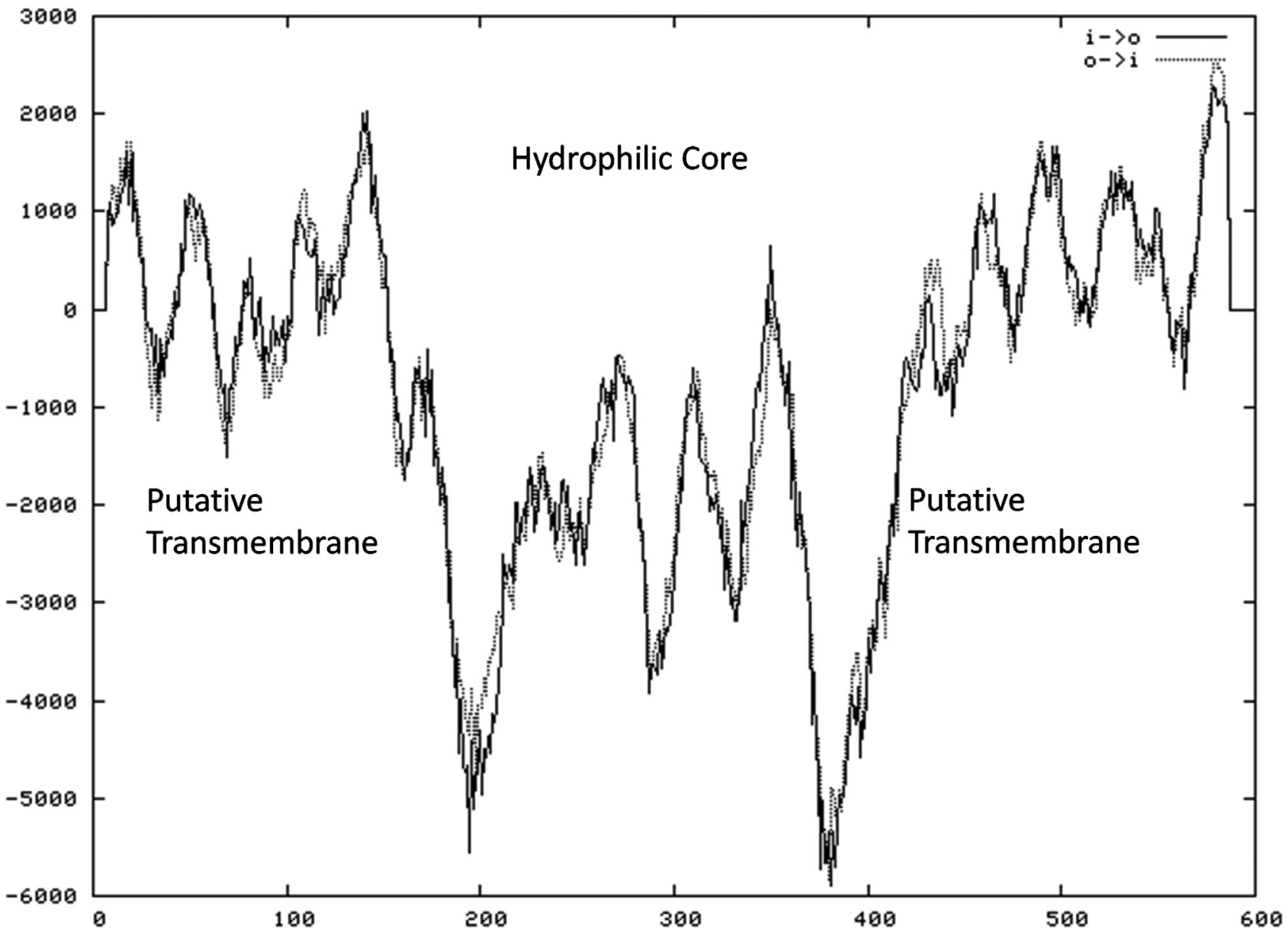

Figure 1 - The membrane-spanning region and its orientation in the PvPIN1 protein as predicted by Tmpred.

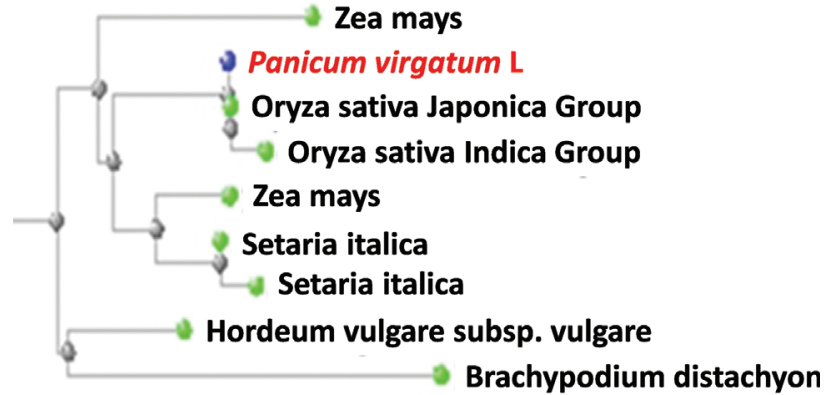

Figure 2 - Phylogenetic analysis of PIN1 genes using the neighbor-joining method based on data collected from the NCBI database.

different molecular weights were observed (Figure 4B). Moreover, the asexually propagated seedlings had similar PCR and hybridization bands, and the PvPIN1 gene was actually inserted in the genome and inherited in subsequent generations.

\section{PVPIN1 gene expression pattern}

To evaluate PvPIN1 gene function during switchgrass development, vegetative tillers were collected from transgenic seedlings and subjected to qRT-PCR. PvPIN1 gene transcript levels were high (2-4-fold increases) in the overexpressed lines and very low (undetectable) in the RNAi lines (Figure 5). This result demonstrates that vector construction and expression successfully generated transgenic plants.

Plant hormone levels were measured by ELISA at the China Agricultural University in Beijing. The IAA (Indole Acetic Acid) levels of wild-type switchgrass and plants with RNAi and PvPINI overexpression were analyzed. The concentrations of auxin in plants with PvPIN1 gene RNAi were increased in the shoot apical meristem and higher than in wild-type plants, whereas the auxin concentration in the stem base was reduced and lower than in wild-type plants. In the overexpression lines, auxin levels were markedly increased in the stem base and significantly higher than in the control and in plants underexpressing PvPIN1. However, in the shoot apical meristem, the auxin levels were slightly elevated rather than reduced (Figure 6).

The effect of PvPIN1 expression on switchgrass tillers was determined by measuring the tiller number (Figure $7 \mathrm{~A}$ ), tiller angle (Figure 7B), root number (Figure 7C) and 

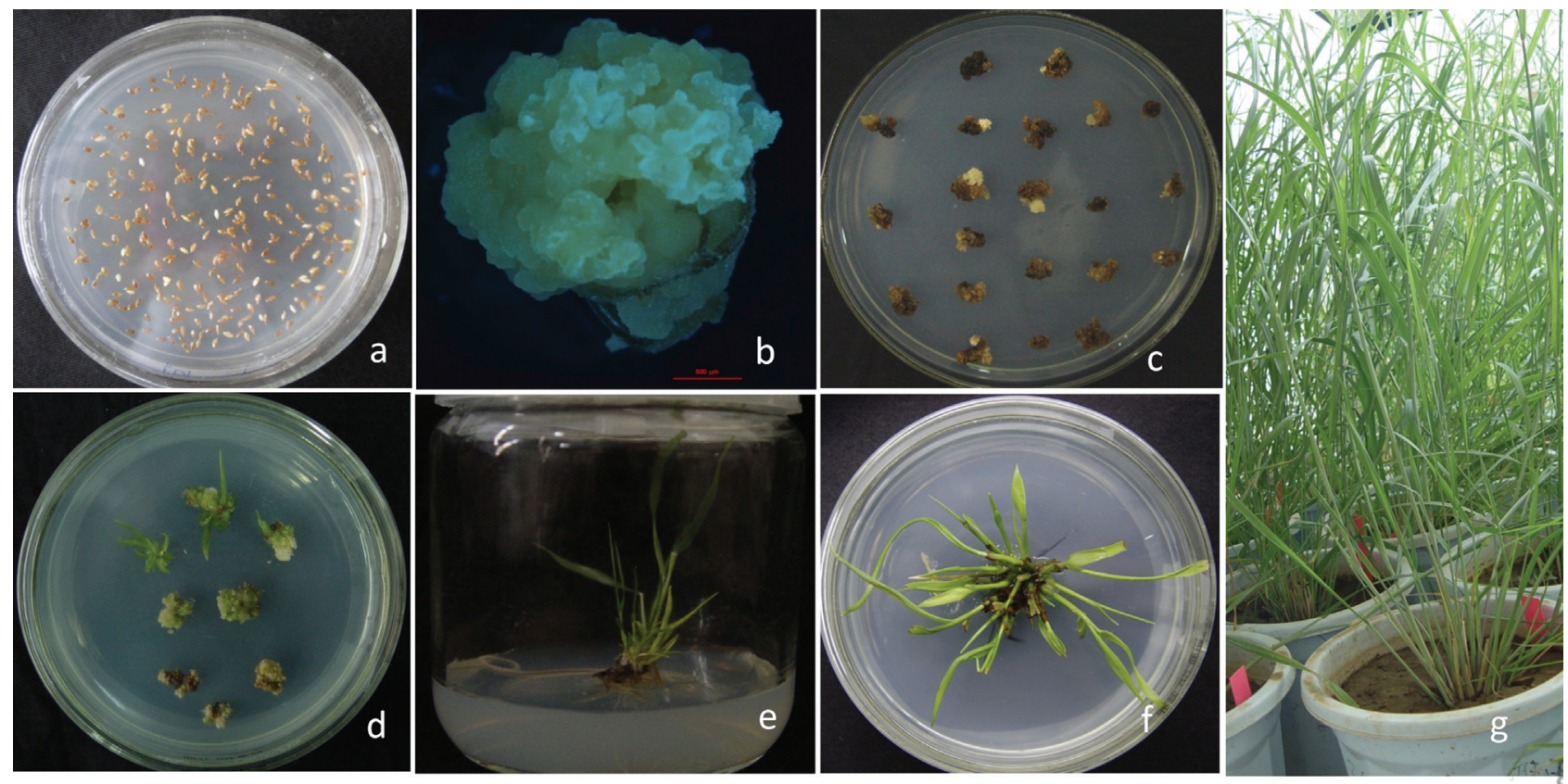

Figure 3 - Transgenic switchgrass (Panicum virgatum L.). (A) Sterilized caryopses placed on induction medium (M5) to stimulate callus growth, (B) Embryogenic calli grown on osmotic medium, (C) Bombarded calli were selected on selection medium, (D) Surviving calli were regenerated on regeneration medium, (E, F) Regenerated seedlings, and (G) Seedlings in a phytotron.

fresh biomass per plant (Figure 7D). In contrast to wildtype plants, PvPIN1 overexpression reduced the tiller number and angle but increased the root number and the fresh biomass per plant. The tiller angles of plants with PvPIN1 RNAi were nearly 1.5 times higher than those in wild-type plants and six times higher than the overexpressing PvPIN1 plants. In contrast, plants underexpressing PvPIN1 showed marked increases in tiller and angle and fresh biomass per plant (Figure 8).
Suppression of PvPIN1 gene expression also promoted lateral bud outgrowth. Consequently, the number of tillers in PvPIN1 RNAi transgenic plants was significantly greater than in control plants. When seedlings overexpressing PvPIN1 were planted on MSB medium with and without TIBA, bud multiplication was more frequent on the former (Figure 9). Treatment with TIBA had a similar effect on wild-type switchgrass, suggesting that underexpression of the PvPINI gene could affect auxin transport.

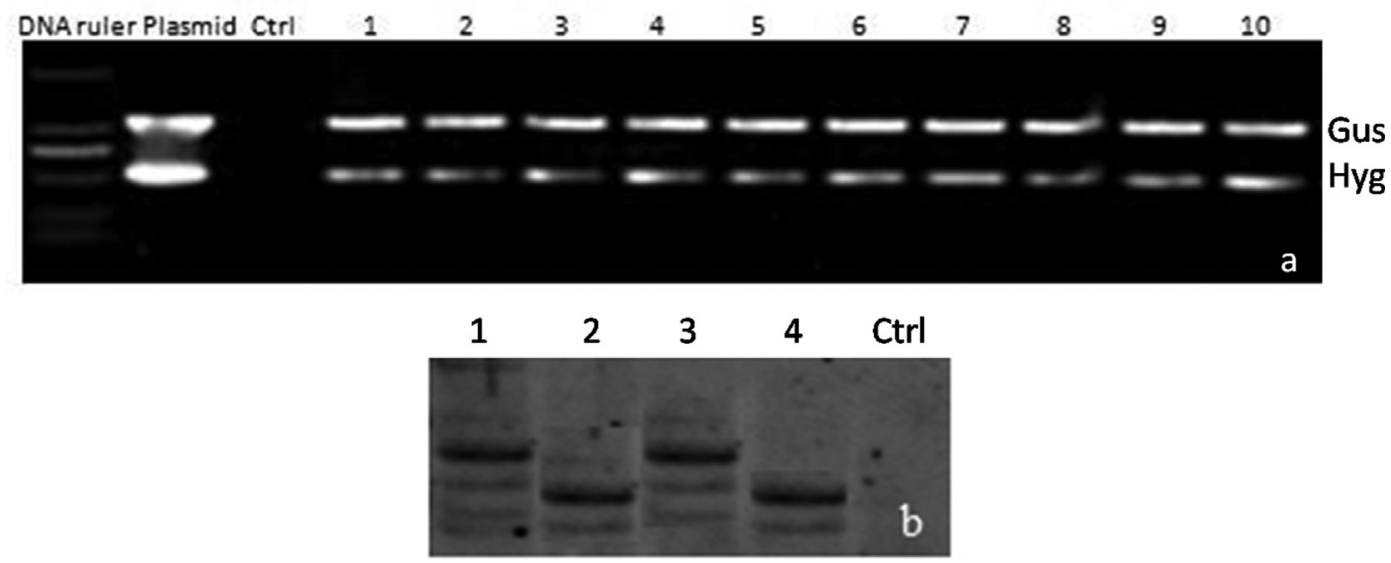

Figure 4 - Molecular characterization of transgenic switchgrass plants. (A) Polymerase chain reaction (PCR) analysis of DNA samples from regenerated switchgrass plants with Gus and Hyg primers. Marker - 2000-bp DNA molecular markers. Plasmid - pTCK303 vector serving as positive control. Ctrl (Control check) - Wild-type plant serving as a negative control. Lanes 1-13 represent PCR products from individual transgenic plants: 1-4 represent PvPIN1-Ri (RNAi of the PvPIN1 gene), 5-8 represent PvPIN1-OE (overexpression of the PvPIN1 gene), 9 represents asexually reproduced seedlings of PvPIN1-Ri, and 10 represents asexually reproduced seedlings of PvPIN1-OE. (B) Southern blot hybridization analysis of the regenerated plants. The blot was hybridized with a DIG-labeled PCR product of the hygromycin gene. Lane 1-PvPIN1-OE, 2-PvPIN1-Ri, 3 and 4 - Asexually propagated plants. 


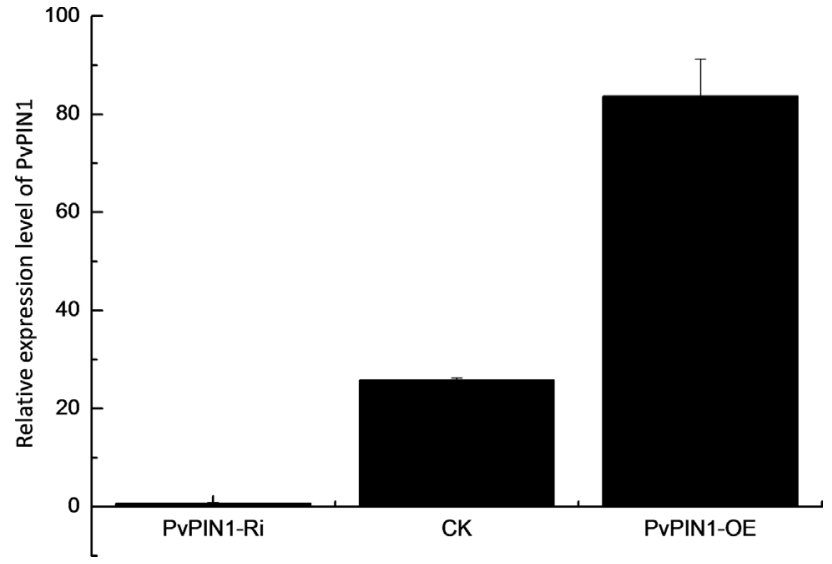

Figure 5 - PvPIN1 gene expression in CK (wild-type) and transgenic switchgrasses. The columns are the mean $\pm \mathrm{SD}(\mathrm{n}=10$ from separate transgenic lines).

\section{Discussion}

Tillering plays an important role in determining crop yield. Seedling tillering is controlled by heredity, photoperiod, soil moisture, light intensity, temperature, mineral nutrition and pruning treatment to simultaneously alter bud and stem development (Moore et al., 1991). Switchgrass is an energy crop with strong tillering capacity. However, compared with other crops, there have been few studies of switchgrass tillers, particularly with regard to the identification of genes that control the tillering process.

The PvPIN1 gene was one of the most highly differentially expressed genes in a pair of transcriptomes from switchgrass tiller mutants that showed significantly lower tiller numbers. PIN1 genes in other plants have been reported to encode polar auxin transport proteins and affect tiller development (Gälweiler et al., 1998; Xu et al., 2005). In the present study, specific primers were designed by comparing the coding sequence of the PvPIN1 gene in switchgrass with those of other PIN1 genes. To predict protein function, the PvPIN1 gene was translated into a 596amino acid protein. Phylogenetic analysis revealed that the putative PvPIN1 protein belonged to the highly conserved PIN1 protein family, the members of which contain a hydrophilic region interconnecting two blocks of transmembrane segments (Palme and Gälweiler, 1999). This finding indicated that the gene of interest was a PIN family gene that may participate in auxin polar transport.
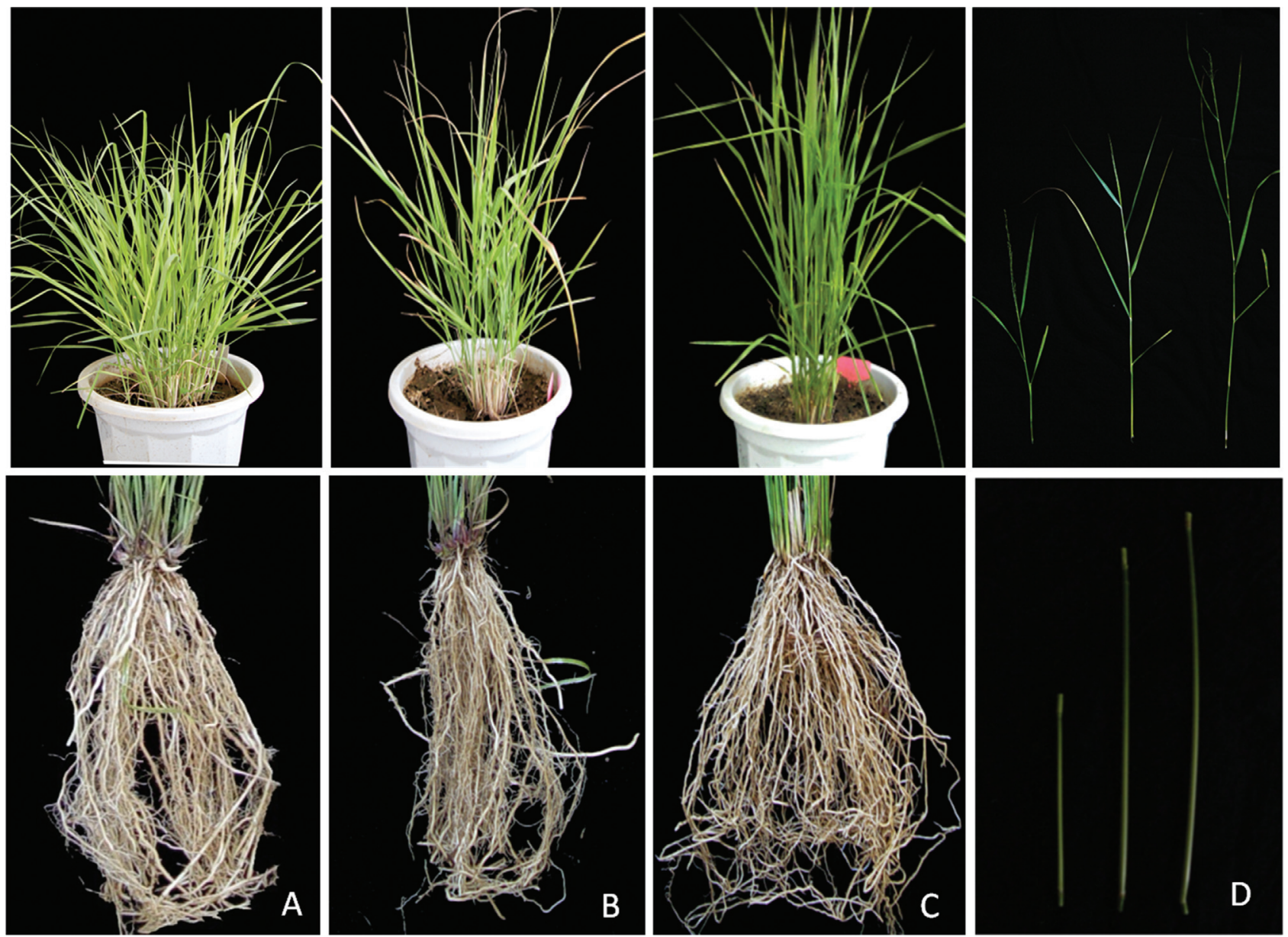

Figure 6 - IAA (Indole-3-acetic acid) concentration (ng/g\&middot;Fresh weight). The columns represent the mean \pm SD $(n=3)$. 


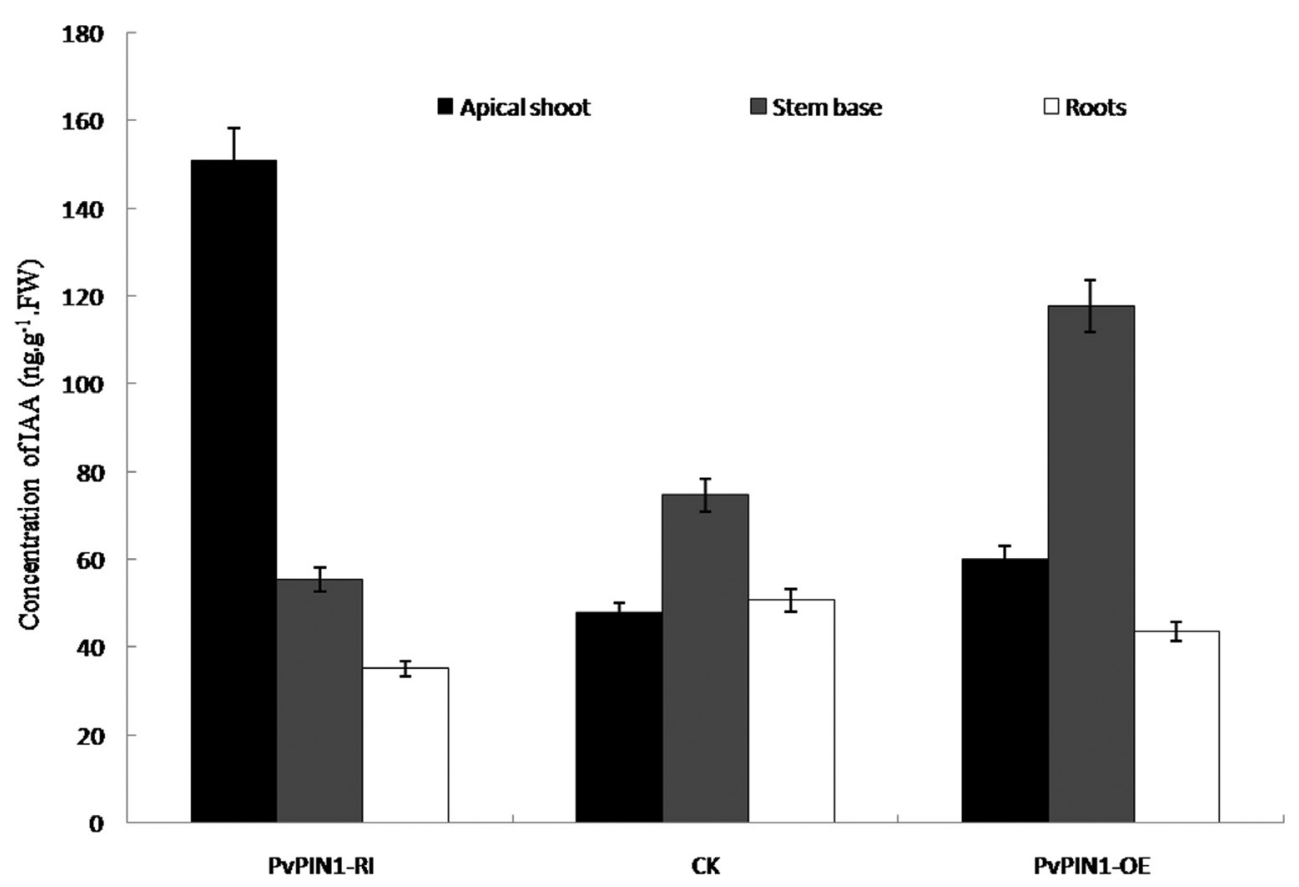

Figure 7 - Phenotype differences between transgenic and wild-type (CK) switchgrass plants. Tiller number (A), tiller angle (B), root number (C) and seedling biomass yield (D) in transgenic and wild-type switchgrasses with different levels of PvPIN1 gene expression. The columns represent the mean \pm $\mathrm{SD}(\mathrm{n}=10)$.
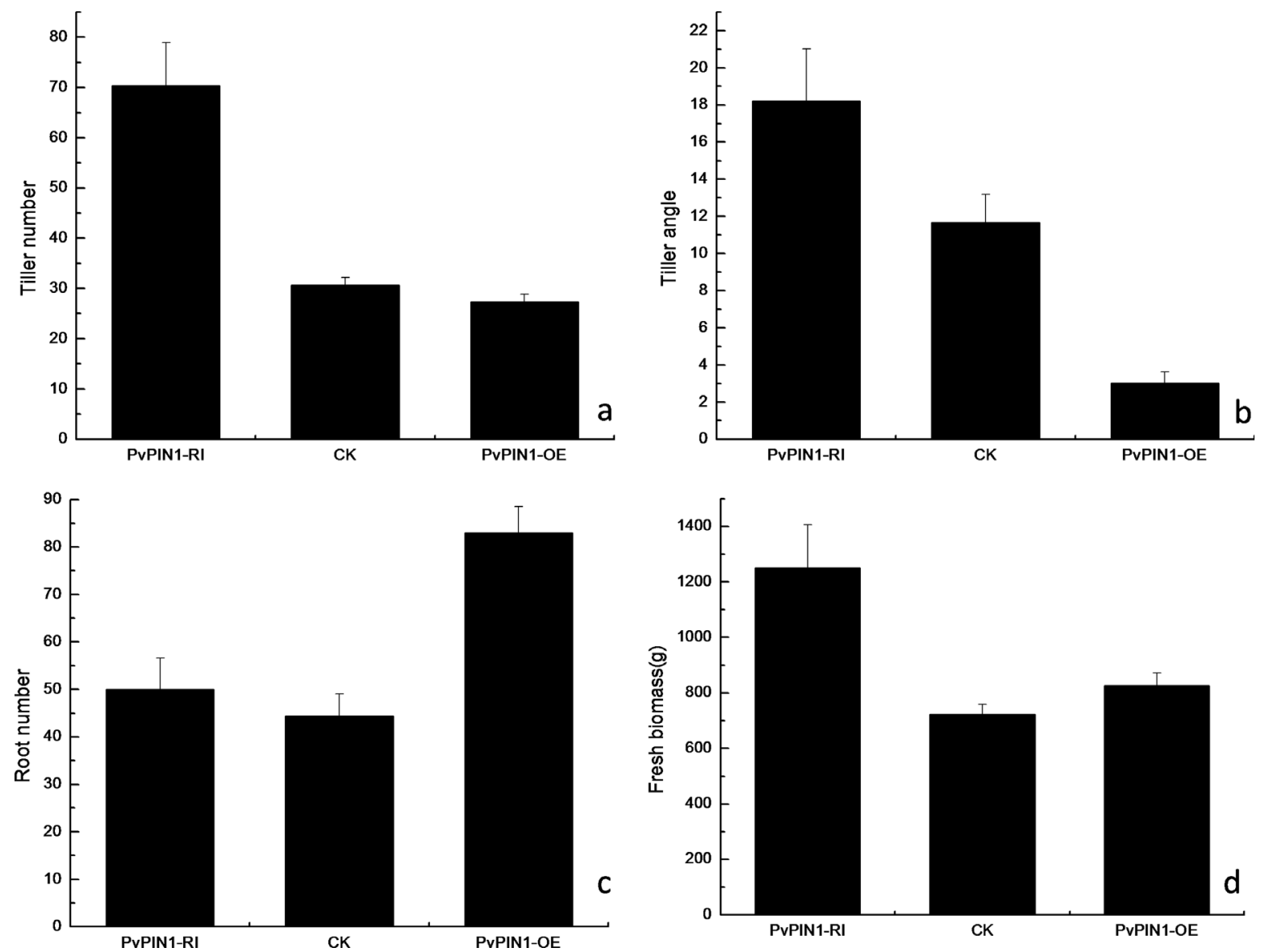

Figure 8 - Transgenic switchgrass phenotypes. (A) PvPNI1-Ri, (B) CK(wild-type), (C) PvPIN1-OE, (D) PvPNI1-Ri (left), CK (wild-type, middle), PvPIN1-OE (right). 


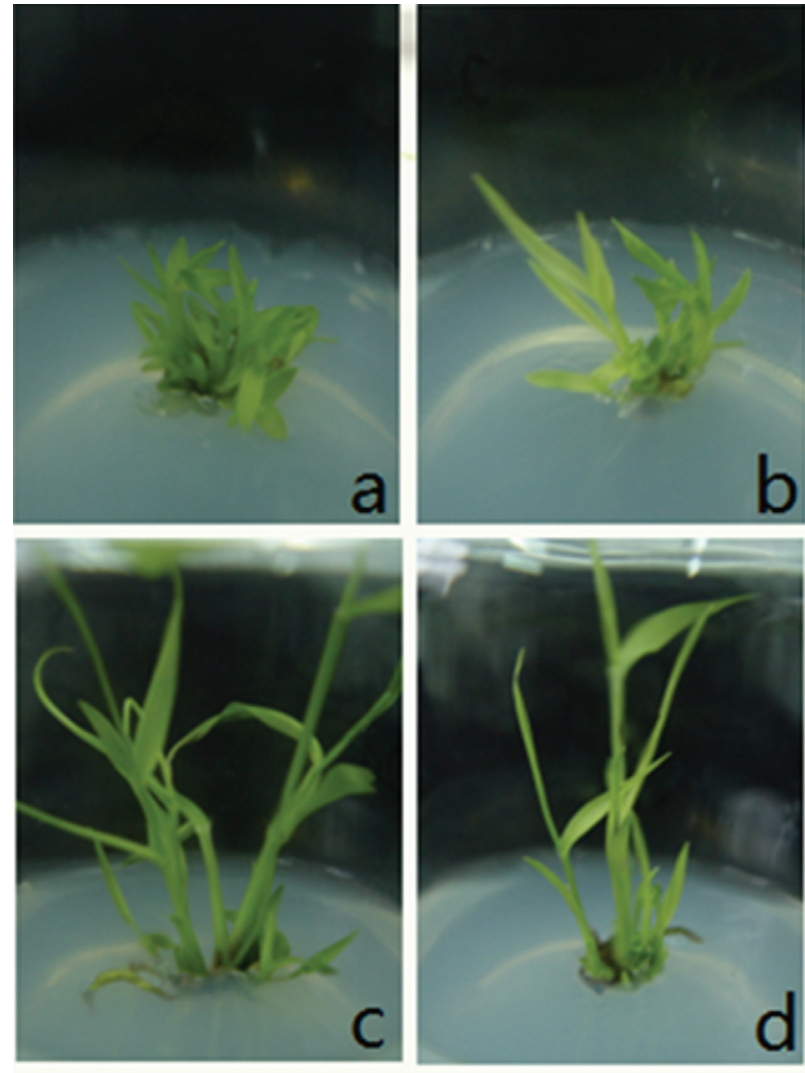

Figure 9 - Phenotypic appearance of (A) TIBA-treated plants, (B) PvPNI1-Ri plants, (C) CK (wild-type) plants and (D) PvPIN1-OE plants.

Tillering in switchgrass is one of the most important processes that directly determine biomass yield (Muir et al., 2001) and has been the principal trait for improving switchgrass breeding programs in past years (Adler et al., 2006). The phenotypes of transgenic switchgrass plants overexpressing the PvPIN1 gene were similar to those of rice overexpressing OsPIN1 (Xu et al., 2005). Specifically, they exhibited few tillers, small tiller angles and more roots. Conversely, reducing PvPIN1 expression increased the tiller number, angle and fresh biomass per plant. In addition, treatment with TIBA, which strongly inhibits auxin efflux (Geldner et al., 2001), effectively blocked the polar transport of auxin and resulted in the same phenotypes as that of plants with reduced $P v P I N 1$ gene expression. These results indicated that the PvPIN1 gene might play a role in polar auxin transport. Because the PvPIN1 gene was predicted to encode a protein for auxin polar transport, differences in the PvPIN1 gene expression patterns could lead to different auxin distributions that might in turn cause variations in plant phenotypes.

In plants treated with RNAi against the PvPIN1 gene, the auxin concentration increased in the shoot apical meristem and decreased in the stem base; this inconsistent pattern led to the outgrowth of more tillers and a larger tillering angle. Conversely, in lines overexpressing PvPIN1, increased auxin levels in the base of the stem resulted in fewer tillers and smaller tillering angles (Figure 7 and Figure 8). Thus, overexpression of PvPIN1 reduced the tiller number and angle and increased the root number, with both of these outcomes being beneficial to plant adaptability and increased biomass (Li et al., 1999). However, in the roots of plants with PvPIN1 underexpression, the auxin levels were decreased but plant primary root length while lateral root numbers were not significantly affected. Studies of Arabidopsis have shown that AtPIN1 plays an essential role in the initiation and development of lateral root primordia (Benková et al., 2003). A similar study reported that underexpression of OSPIN1 by RNAi in rice reduced the number of adventitious roots (Geldner et al., 2001).

To further elucidate the reason underlying these differences, root auxin levels were measured and found not to be significantly different between the two transgenic switchgrass plants. One possible explanation for this is that there are other PIN1 genes in switchgrass, as has been reported in rice (Wang et al., 2009). These PINl genes may be functionally complementary in controlling the development of later roots. PIN1 gene functions in switchgrass need to be studied further. It is thought that five PIN genes control auxin distribution to regulate cell division and cell expansion in the primary root (Blilou et al., 2005). However, another report concluded that little auxin is synthesized in the root; rather, most auxin in the root is obtained from the ground by acropetal translocation (Swarup et al., 2001). This mode of nonpolar transport of auxin in the phloem occurs in many plants (Goldsmith et al., 1974; Friml, 2003). The use of other transportation mechanisms may help to maintain the auxin gradient and regulate plant development.

In conclusion, we found that switchgrass PvPIN1 acts as a polar auxin transporter based on the predicted protein structure, transgenic switchgrass phenotypes and TIBA treatment results. Switchgrass is an allogamous crop that is strongly self-incompatible (Talbert et al., 1983) and its different genetic backgrounds make the verification of gene function challenging. Fortunately, we obtained a large number of transgenic plants and were able to perform statistical analyses to eliminate inter-individual differences in our experiments. To our knowledge, this is the first report to describe the sequence of the PIN1 gene and its functions in switchgrass. The finding that PvPIN1 is involved in auxin-dependent tillering emergence and adventitious root development provides new insight into the function of the PIN1 family and should encourage the study of tillering in switchgrass.

\section{Acknowledgments}

We thank Li Quan for providing valuable suggestions that helped improve the manuscript. This work was supported by the Natural Science Foundation of China (grant nos. 31171607 and 31371690). 


\section{References}

Adler PR, Sanderson MA, Boateng AA, Weimer PJ and Jung HG (2006) Biomass yield and biofuel quality of switchgrass harvested in fall or spring. Agron J 98:1518-1525.

Benková E, Michniewicz M, Sauer M, Teichmann T, Seifertová D, Jürgens G and Friml J (2003) Local, efflux-dependent auxin gradients as a common module for plant organ formation. Cell 115:591-602.

Blilou I, Xu J, Wildwater M, Willemsen V, Paponov I, Friml J, Heidstra R, Aida M, Palme K and Scheres B (2005) The PIN auxin efflux facilitator network controls growth and patterning in Arabidopsis roots. Nature 433:39-44.

Casler MD (2012) Switchgrass breeding, genetics, and genomics. In: Monti A (ed) Switchgrass. Springer, New York, pp 29-53.

Chatfield SP, Stirnberg P, Forde BG and Leyser O (2000) The hormonal regulation of axillary bud growth in Arabidopsis. Plant J 24:159-169.

Chen Y, Fan X, Song W, Zhang Y and Xu G (2012) Overexpression of OsPIN2 leads to increased tiller numbers, angle and shorter plant height through suppression of OsLAZY1. Plant Biotechnol J 10:139-149.

Crozier A, Kamiya Y, Bishop GJ and Yokota T (2000) Biosynthesis of hormones and elicitor molecules. In: Buchanan BB, Gruissem W and Gones RL (eds) Biochemistry and Molecular Biology of Plants. Wiley, Hoboken, NJ, pp 884-994.

Forestan C and Varotto S (2010) PIN1 auxin efflux carriers localization studies in Zea mays [J]. Plant Signal Behav 5:436439.

Friml J (2003) Auxin transport - shaping the plant. Curr Opin Plant Biol 6:7-12.

Friml J, Vieten A, Sauer M, Weijers D, Schwarz H, Hamann T, Offringa R and J1rgens G (2003) Efflux-dependent auxin gradients establish the apical-basal axis of Arabidopsis. Nature 426:147-153.

Gälweiler L, Guan C, M1ller A, Wisman E, Mendgen K, Yephremov A and Palme K (1998) Regulation of polar auxin transport by AtPIN1 in Arabidopsis vascular tissue. Science 282:2226-2230.

Geldner N, Friml J, Stierhof YD, J1rgens G and Palme K (2001) Auxin transport inhibitors block PIN1 cycling and vesicle trafficking. Nature 413:425-428.

Goldsmith MH, Cataldo DA, Karn J, Brenneman T and Trip P (1974) The rapid non-polar transport of auxin in the phloem of intact Coleus plants. Planta 116:301-317.

Huang F, Zago MK, Abas L, van Marion A, Galvø̨n-Ampudia CS and Offringa R (2010) Phosphorylation of conserved PIN motifs directs Arabidopsis PIN1 polarity and auxin transport. Plant Cell 22:1129-1142.

Leyser O (2003) Regulation of shoot branching by auxin. Trends Plant Sci 8:541-545.

Li ZK, Paterson AH, Pinson SRM and Stansel JW (1999) RFLP facilitated analysis of tiller and leaf angles in rice (Oryza sativa L.). Euphytica 109:79-84.

Luschnig C, Gaxiola RA, Grisafi P and Fink GR (1998) EIR1, a root-specific protein involved in auxin transport, is required for gravitropism in Arabidopsis thaliana. Genes Dev 12:2175-2187.

Moore KJ, Moser LE, Vogel KP, Waller SS, Johnson BE and Pedersen JF (1991) Describing and quantifying growth stages of perennial forage grasses. Agron J 83:1073-1077.
Muday GK and DeLong A (2001) Polar auxin transport: controlling where and how much. Trends Plant Sci 6:535-542.

Muir JP, Sanderson MA, Ocumpaugh WR, Jones RM and Reed RL (2001) Biomass production of 'Alamo' switchgrass in response to nitrogen, phosphorus, and row spacing. Agron J 93:896-901.

Okada K, Ueda J, Komaki MK, Bell CJ and Shimura Y (1991) Requirement of the auxin polar transport system in early stages of Arabidopsis floral bud formation. Plant Cell 3:677-684.

Palme K and Gälweiler L (1999) PIN-pointing the molecular basis of auxin transport. Curr Opin Plant Biol 2:375-381.

Paponov IA, Trebar M, Palme K, Blilou I and Teale WD (2005) The PIN auxin efflux facilitators: evolutionary and functional perspectives. Trends Plant Sci 10:170-177.

Parrish DJ, Casler MD and Monti A (2012) The evolution of switchgrass as an energy crop. In: Monti A (ed) Switchgrass. Springer, New York, pp 1-28.

Paterson AH, Bowers JE, Bruggmann R, Dubchak I, Grimwood J, Gundlach H, Haberer G, Hellsten U, Mitros T, Poliakov A, et al. (2009) The Sorghum bicolor genome and the diversification of grasses. Nature 457:551-556.

Reinhardt D, Pesce ER, Stieger P, Mandel T, Baltensperger K, Bennett M, Traas J, Friml J and Kuhlemeier C (2003) Regulation of phyllotaxis by polar auxin transport. Nature 426:255-260.

Rosen E, Chen R and Masson pH (1999) Root gravitropism: a complex response to a simple stimulus? Trends Plant Sci 4:407-412.

Seo PJ, Xiang F, Qiao M, Park JY, Lee YN, Kim SG, Lee YH, Park WJ and Park CM (2009) The MYB96 transcription factor mediates abscisic acid signaling during drought stress response in Arabidopsis. Plant Physiol 151:275-289.

Song GQ, Walworth A and Hancock JF (2012) Factors influencing Agrobacterium-mediated transformation of switchgrass cultivars. Plant Cell Tiss Organ Cult 108:445-453.

Swarup R, Friml J, Marchant A, Ljung K, Sandberg G, Palme K and Bennett M (2001) Localization of the auxin permease AUX1 suggests two functionally distinct hormone transport pathways operate in the Arabidopsis root apex. Genes Dev 15:2648-2653.

Talbert LE, Timothy DH, Burns JC, Rawlings JO and Moll RH (1983) Estimates of genetic parameters in switchgrass. Crop Sci 23:725-728.

Vain P, McMullen MD and Finer JJ (1993) Osmotic treatment enhances particle bombardment-mediated transient and stable transformation of maize. Plant Cell Rep 12:84-88.

Varvel GE, Vogel KP, Mitchell RB, Follett RF and Kimble JM (2008) Comparison of corn and switchgrass on marginal soils for bioenergy. Biomass Bioenerg 32:18-21.

Vernoux T, Kronenberger J, Grandjean O, Laufs P and Traas J (2000) PIN-FORMED 1 regulates cell fate at the periphery of the shoot apical meristem. Development 127:5157-5165.

Wang Z, Chen CB, Xu YY, Jiang RX, Han Y, Xu ZH and Chong K (2004) A practical vector for efficient knockdown of gene expression in rice (Oryza sativa L.). Plant Mol Biol Rep 22:409-417.

Wang D, Pajerowska-Mukhtar K, Culler AH and Dong X (2007) Salicylic acid inhibits pathogen growth in plants through repression of the auxin signaling pathway. Curr Biol 17:1784-1790. 
Wang JR, Hu H, Wang GH, Li J, Chen JY and Wu P (2009) Expression of PIN genes in rice (Oryza sativa L.): tissue specificity and regulation by hormones. Mol Plant 2:823-831.

Weijers D and Jürgens G (2005) Auxin and embryo axis formation: the ends in sight? Curr Opin Plant Biol 8:32-37.

Wisniewska J, Xu J, Seifertová D, Brewer PB, Ruzicka K, Blilou I, Rouquié D, Benková E, Scheres B and Friml J (2006) Polar PIN localization directs auxin flow in plants. Science 312:883-883.

Xi YJ, Fu CX, Ge YX, Nandakumar R, Hisano H, Bouton J and Wang ZY (2009) Agrobacterium-mediated transformation of switchgrass and inheritance of the transgenes. Bioenerg Res 2:275-283.
Xu M, Zhu L, Shou H and Wu P (2005) A PIN1 family gene, OsPIN1, involved in auxin-dependent adventitious root emergence and tillering in rice. Plant Cell Physiol 46:16741681.

Yang YM, Xu CN, Wang BM and Jia JZ (2001) Effects of plant growth regulators on secondary wall thickening of cotton fibres. Plant Growth Regul 35:233-237.

Zhou DX, Yin K, Xu ZH and Xue HW (2003) Effect of polar auxin transport on rice root development. Acta Bot Sin 45:1421-1427.

Associate Editor: Adriana S. Hemerly

License information: This is an open-access article distributed under the terms of the Creative Commons Attribution License (type CC-BY), which permits unrestricted use, distribution and reproduction in any medium, provided the original article is properly cited. 